\title{
DA FILOSOFIA E DO FILOSOFAR AO SEU ENSINO A PROPÓSITO DE ENSINAR FILOSOFIA? O QUE DIZEM OS FILÓSOFOS ${ }^{1}$
}

João Maria André

1.

O Centro de Filosofia da Universidade de Lisboa, no âmbito de um projecto financiado pela FCT sobre "ensino/aprendizagem da Filosofia", acaba de publicar esta colectânea de textos e comentários com coordenação de Maria José Vaz Pinto e Maria Luísa Ribeiro Ferreira, que coordenam também aquele projecto de investigação e que já havia proporcionado a publicação anterior de Ensinar e aprender Filosofia num mundo em rede. Não podemos deixar, de, em primeiro lugar, saudar tanto esta publicação como a anterior, que vêm enriquecer consideravelmente os materiais de estudo e reflexão no âmbito da problemática da natureza da Filosofia, do seu ensino e da sua aprendizagem, a partir das posições explicitamente assumidas por alguns dos vultos da nossa tradição filosófica e das contextualizações e reflexões de numerosos professores e investigadores de Filosofia, que, ao mesmo tempo que são reconhecidos especialistas nos autores dos textos seleccionados, para o caso do volume que agora estamos a apresentar, são também mestres no ensino da Filosofia: mestres preocupados com as dinâmicas desse mesmo ensino e com as estratégias para fazer dele uma iniciação ao pensamento filosófico, entendendo a expressão "pensamento filosófico" tanto no seu significado objectivo, como o resultado de uma actividade reflexiva, crítica, questionante e filosofante, como na sua dimensão activa e processual, como praxis em permanente exercício de interrogação do mundo, do homem, dos seus sentidos e das linguagens com que se traduzem esses mesmos sentidos.

\footnotetext{
${ }^{1}$ Maria José Vaz PINTO e Maria Luísa Ribeiro FERREIRA (coord.). Ensinar Filosofia? O que dizem os filósofos. Lisboa: Centro de Filosofia da Universidade de Lisboa, 2013.
}

Philosophica, 43, Lisboa, 2014, pp. 135-146. 
Saudando, assim, esta publicação e sublinhando a sua importância, devemos em primeiro lugar reconhecer que nos encontramos perante um salutar exercício de pluralismo filosófico. Esse pluralismo filosófico resulta, antes de mais, da inscrição histórica dos autores seleccionados como referências e testemunhos sobre a educação, a filosofia, o filosofar e o respectivo ensino: cinco pensadores da Antiguidade, três pensadores medievais, dois pensadores renascentistas, cinco pensadores da Idade Moderna, cinco pensadores na transição da época moderna para a época contemporânea e vinte e dois pensadores que se podem considerar nossos contemporâneos. Fica, deste modo, demonstrado que a preocupação com a dimensão comunicativa da Filosofia e do acto de filosofar e com a respectiva interiorização e aprendizagem (digamos assim e não recorrendo apenas à expressão "ensino da filosofia" que, em função dos textos seleccionados e dos comentários produzidos, se revelaria demasiado restritiva) é uma preocupação que tem atravessado todos os tempos históricos, desde que a figura do filósofo emergiu na sua autonomia e no seu estatuto no panorama do saber e dos saberes, da cultura e das culturas, da educação e dos seus sujeitos (prefiro utilizar esta palavra em vez da palavra "agente", com uma conotação mais técnica e, de algum modo, instrumental). São, naturalmente, em maior número os filósofos contemporâneos mobilizados; todavia, esse relevo dado aos que, no século $\mathrm{XX}$, se debruçaram sobre esta questão tem a sua justificação, por um lado, no facto de a escolaridade da Filosofia, sobretudo ao nível do ensino secundário, se ter alargado e implementado mais no século XX do que nos séculos anteriores, e, por outro lado, porque a auto-reflexividade dos filósofos sobre a dimensão comunicativa do seu saber se intensificou consideravelmente nas últimas décadas, acompanhando uma igual intensificação do desenvolvimento das ciências da educação e das suas implicações pedagógicas no âmbito do ensino das diversas disciplinas. Isso não significa que alguns dos textos mais pertinentes para o assunto em questão não sejam justamente textos de autores modernos, como os textos, acompanhados dos respectivos comentários, de Espinosa e Kant, ou de autores do século XIX, como os textos, também acompanhados dos pertinentes comentários, de Hegel ou Feuerbach. Mas o pluralismo filosófico desta colectânea e antologia diz também respeito às tendências em que se integram tanto os filósofos seleccionados, como os comentadores que os apresentam e que com eles dialogam. Se ao nível da tradição histórica encontramos pensadores representantes do idealismo platónico, da filosofia cristã, nalguns casos marcadamente apologética, do racionalismo ou do idealismo alemão, encontramos também, na contemporaneidade, filósofos e comentadores que se inscrevem no âmbito do pensamento da crítica, da suspeita e da desconstrução, das tradições continen- 
tais, da tradição fenomenológica e da tradição analítica, e até de correntes mais ou menos inspiradas por epistemologias feministas. E, como teremos oportunidade de ver, em muitos casos assistimos, de uns textos para outros e de uns comentários para outros, à emergência da controvérsia, mostrando que o próprio terreno do ensino da Filosofia é um campo fértil para o diálogo, para a argumentação e contra-argumentação, que o leitor pode ir fazendo à medida que avança nas leituras e no aprofundamento das reflexões que elas proporcionam. Um outro índice da pluralidade que marca esta colectânea tem a ver com a origem dos pensadores seleccionados: gregos, latinos, italianos, franceses, alemães, ingleses, irlandeses, norte-americanos, espanhóis e, ainda, cinco pensadores portugueses, além de um luso-uruguaio, para mostrar que em terras lusas a questão da filosofia e da sua aprendizagem não andou arredada das preocupações de quem pensou ou escreveu na língua de Camões. E, para mostrar que a problemática da natureza da Filosofia e do seu ensino não se escreveu apenas no masculino, há que registar o cuidado colocado em apresentar também o testemunho de algumas pensadoras que a este tema dedicaram a sua atenção, ou não fosse uma das organizadoras desta colectânea uma das investigadoras que, entre nós, mais se tem preocupado com a questão do género na filosofia e, sobretudo, na sua prática. A pluralidade caracteriza ainda, finalmente, a forma como cada comentador interpretou a sua tarefa. O formato geral proposto é, a todos os títulos, muito interessante e merece ser destacado: uma apresentação do texto do respectivo autor, uma contextualização do texto seleccionado e um comentário. Deu, além disso, lugar a desenvolvimentos diferentes: em muitos casos houve mesmo uma contextualização na vida e obra do autor do texto escolhido, seguido de um comentário muito próximo das principais ideias do texto. Noutros casos, sobretudo naqueles em que o texto não era tão explícito sobre as respectivas consequências para a problemática do ensino da Filosofia, o trabalho do comentador foi tirar as respectivas ilações, por exemplo de um determinado conceito de Filosofia ou de uma determinada noção de educação, e mostrar as suas repercussões na concepção do ensino da Filosofia. Noutros casos ainda, o texto foi um pretexto para que o comentador pudesse reflectir sobre as condições actuais do ensino e da aprendizagem da Filosofia na actualidade. Registo, no entanto, que, em três casos, o formato geral não foi inteiramente respeitado na distinção entre a apresentação de um texto seleccionado na sua integralidade e o subsequente comentário, optando o comentador por desenvolver o tema no autor seleccionado, através de reflexões e interpretações pessoais cruzadas com citações do texto. É certo que esses terão sido escritos inicialmente com outro objectivo que não a integração nesta colectânea, o que justifica a fuga ao formato geral. Mas não é tanto 
a quebra da uniformidade que chama mais a minha atenção (seria também um formato possível), mas mais a sua própria articulação com as metodologias do ensino da Filosofia. Apresentar o texto integral em primeiro lugar e fazer depois um comentário é dar liberdade ao leitor para estabelecer ele um diálogo com o próprio texto, o que me parece hermenêuticamente mais adequado e fecundo, no contexto de um livro sobre o ensino e a aprendizagem da Filosofia, do que estabelecer, desde o início, a mediação do intérprete-comentador, dificultando ou impedindo o acesso directo ao texto e, assim, introduzindo alguns obstáculos ao diálogo filosófico a que ele apela. Mas este outro formato não deixa, por outro lado, de ser também um acesso possível, sobretudo a autores cujos textos sobre o tema em causa são marcados por alguma dispersão ou por uma complexidade significativa.

É, portanto, plural, sob diversos pontos de vista, o trabalho de reunião de textos de filósofos e de comentários a esses textos que esta obra representa, o que, já por si, indicia que no coração do filosofar e da sua aprendizagem se inscreve a diferença, a diversos níveis, e que sem um respeito por essa diferença não há um respeito pela própria Filosofia e pelo próprio filosofar. E como a diferença é a condição indispensável par um verdadeiro diálogo, significa isto que a pluralidade de que se reveste este livro postula o diálogo como seu complemento e como forma de consumar o que nele permanentemente se afirma como latente e como imperativo do próprio pensar.

Claro que uma selecção, ao mesmo tempo que significa uma inclusão, significa, sempre, uma certa prática de exclusão, por diferentes motivos que não são motivos necessariamente relacionados com desvalorizações, subalternidades ou discriminações negativas. Por isso, se há muitos pensadores e algumas pensadoras que foram aqui incluídos, outras e outros há que não puderam, por diversas razões, estar presentes. Sendo um dos meus campos privilegiados de investigação a Filosofia do Renascimento, não posso deixar de registar algumas ausências, não propositadas, acredito, a começar pelo autor ao qual mais tempo dediquei a atenção, Nicolau de Cusa, cujo conceito de "douta ignorância" acompanhado da prática da "manuductio" a que repetidamente faz referência, poderiam ter um lugar nesta memória dos autores que se dedicaram ao problema do ensino da Filosofia, ou o próprio Pico della Mirandola no seu debate entre retórica e filosofia. Por diferentes razões, também é visível a ausência de qualquer autor que se tenha perfilado numa orientação marxista, sobretudo quando um dos grandes mestres deste centro de investigação é um dos maiores conhecedores, neste país, do pensamento de Marx, ou autores com uma orientação existencialista, no contexto da qual se desenvolveram algumas das tendências do pensamento dialógico mais importantes 
do século XX. Argumentar-se-á com o desconhecimento de textos de Marx sobre esta problemática; no entanto, como teremos oportunidade de demonstrar, esta colectânea não reúne apenas textos explicitamente sobre o ensino e a aprendizagem da Filosofia, sendo muitos dos textos seleccionados, quer dos autores da tradição histórico-filosófica, quer dos autores mais contemporâneos, e tanto de autores estrangeiros, como de autores especificamente portugueses, não propriamente textos sobre o ensino da Filosofia, mas textos sobre a natureza da Filosofia, daí retirando os comentadores pretexto para falarem acerca do ensino da Filosofia.

Uma nota ainda, neste contexto e a propósito da pluralidade, para sublinhar uma clara orientação, na organização da colectânea, pela tradição do que podemos chamar o pensamento ocidental. Há, naturalmente, quem entenda que a Filosofia começou por falar grego e é uma prática reflexiva e discursiva marcadamente europeia nas suas origens e ocidental no seu desenvolvimento. Por esse motivo, entende-se esta opção como uma opção legítima e sustentável. No entanto, há posições diferentes que questionam a redução do pensar filosófico e do amor à sabedoria que lhe está subjacente ao pensamento europeu ou norte-americano. Poderemos encontrar outros testemunhos diferentes sobre a aprendizagem do saber e sobre a educação quer na tradição histórico-filosófica, em que a filosofia árabe ou a judaica desempenharam um papel incontornável no pensamento filosófico do ocidente, quer na contemporaneidade, em que os contactos com os mestres da sabedoria oriental, tanto indiana como chinesa ou japonesa lançam desafios fecundos à maneira europeia de olhar o mundo e de pensar o ensino e a educação, ou em que os desenvolvimentos de um pensamento próprio nas matrizes conceptuais africanas ou sul-americanas desafiam o sujeito moderno que se afirmou como conquistador e colonizador e fez do pensamento uma arma ao serviço desse projecto. Ficamos, por isso, à espera de um segundo volume que complete, numa dinâmica intercultural que também me é cara, esta perspectivação mais ocidentalizante do que é a Filosofia, o seu ensino e a sua aprendizagem.

\section{2.}

Aparece este livro com o título: Ensinar Filosofia? O que dizem os filósofos. Poderia pensar-se que tanto os autores selecionados e bem assim os respectivos textos como os comentários se restringem à resposta a esta pergunta. Não é exactamente assim e a sua justificação está no facto de que a resposta a tal pergunta, para poder respeitar a complexidade do que está em causa, envolve muitas outras perguntas e muitas outras respostas e, por esse motivo, ainda bem que a colectânea não se limita a apresentar textos explicitamente e directamente relacionados com 
a problemática do ensino da Filosofia. Em primeiro lugar, falar do ensino da Filosofia ou do filosofar implica falar também da aprendizagem da Filosofia e do filosofar e da iniciação filosófica. Ora uma pode ser a dinâmica do ensinar e outra a dinâmica do aprender. O ensino da Filosofia supõe sempre a presença de um mestre (aquele que ensina) directamente ou pela mediação dos seus textos, enquanto a aprendizagem da Filosofia pode ser feita sem mestre nesse sentido, embora não dispense o contacto com o pensamento dos grandes mestres do passado. Não há, assim, uma reciprocidade entre ensinar e aprender filosofia e alguns dos textos escolhidos dão conta dessa diferença. Além disso, a primeira coisa que está em questão quando se fala do ensino ou da aprendizagem da Filosofia é a própria noção de Filosofia, a natureza intrínseca desse saber e desse discurso a que chamamos filosófico, as suas componentes, as suas dimensões, nomeadamente a sua dimensão dialógica e comunicativa (pois que sentido teria falar de ensino da Filosofia se não se reconhecesse no pensamento e no saber filosófico uma profunda dimensão comunicativa?). Por esse motivo, há um número significativo de textos que, mais do que preocupar-se em responder à questão do ensino da Filosofia, responde à questão da própria natureza da Filosofia. Em terceiro lugar, todo o ensino e toda a aprendizagem da Filosofia e do filosofar são parte de um processo mais vasto que é o processo educativo. Responder à questão do ensino da Filosofia supõe, assim, também, uma resposta à questão do que é educar e também, em termos gerais, do que é o ensino. Finalmente, porque muito do ensino da Filosofia e do filosofar e muita da aprendizagem da Filosofia e do filosofar têm como referência fundamental os textos, não é de admirar que algumas das respostas a esta questão passem principalmente por uma resposta à problemática da leitura e da interpretação dos textos ou pelo estabelecimento da relação entre filosofia e literatura. Ou seja, o conjunto de textos e comentários que aqui são apresentados ultrapassam em muito a questão específica do ensino da Filosofia para suscitarem ou desencadearem uma profunda reflexão sobre a essência do próprio acto de filosofar e a sua dimensão educativa. Daí que o título, se é adequado ao material que nos proporciona, também poderia ter encontrado uma outra formulação, talvez mais expressiva das abordagens realizadas, como seria: "Da filosofia e do filosofar ao seu ensino e aprendizagem". Assim, tentando fazer uma arrumação das diferentes tendências ou dos diferentes conteúdos que marcam com maior centralidade cada um dos contributos da colectânea, trabalho que não é fácil, dado que alguns textos se movimentam simultaneamente em vários registos, podemos constatar que o maior número é mesmo o daqueles que se dedicam especificamente a responder à questão do título Ensinar Filosofia?. Situaria neste grupo um conjunto de 18 textos e autores, mais 
especificamente os contributos de e sobre Musonius Rufus, Santo Agostinho, Espinosa, Kant, Hegel, Schopenhauer, Feuerbach, Carlos Vaz Ferreira, Ortega y Gasset, António Sérgio, Maria Zambrano, Álvaro Ribeiro, Lévinas, Matthew Lippman, Mary Warnock, Lyotard, Deleuze e Derrida. Há depois um pequeno conjunto de textos, e comentários, em que o tema central já não é propriamente o do ensino da filosofia, mas o da aprendizagem da filosofia, que como já referimos, é algo de relativamente distinto. Situaria neste caso tanto o texto de Tomás de Aquino, como o texto de Descartes. Não envolvendo já directamente a dinâmica pedagógica, um outro conjunto de textos debruça-se especialmente acerca da definição da filosofia, da sua natureza e das suas dimensões, cabendo em alguns destes casos aos comentadores ou intérpretes tirar as respectivas consequências pedagógico-didácticas. É o segundo grupo mais numeroso (12 ao todo) e dele fazem parte os contributos de ou a propósito de autores como Platão, Aristóteles, Epicuro, Plotino, Coménio, Leibniz, Schelling, Heidegger, Agostinho da Silva, Simone Weil, Paul Ricoeur e Michel Foucault. Em alguns casos, o contributo recolhido não se inscreve nem especificamente na problemática do ensino ou da aprendizagem da Filosofia, nem na da natureza da Filosofia, mas versa, em termos mais gerais, ou sobre o ensino ou sobre a educação, mobilizando, quando muito, o significado e o alcance educativo da Filosofia e da sua iniciação. Não deixa de ser uma problemática igualmente importante, na medida em que quando se reflecte sobre o ensino da Filosofia no contexto geral educativo, é indispensável equacionar os objectivos, a natureza e as estratégias gerais da educação. Aproximam-se mais desta perspectiva os 7 textos de Pedro da Fonseca, Rousseau, Nietzsche, Russell, José Marinho, Michel Serres e John Searle. Finalmente, os contributos de Boaventura, de Hannah Arendt ou de Iris Murdoch tocam aspectos mais periféricos, no primeiro caso, referentes à interpretação da escritura, com aplicações à Hermenêutica de outros textos, no segundo à articulação entre Filosofia, Cultura e Consumo, e, no terceiro caso, referentes às diferenças e semelhanças entre o discurso filosófico e o discurso literário. Podemos concluir, pois, que, apesar de polarizadas pela problemática do ensino e da aprendizagem da Filosofia, é um leque bastante diversificado de questões aquele que nestes textos se abre e que os materiais recolhidos, assim como os excelentes comentários que normalmente os acompanham constituem uma fonte de recursos tanto para professores de Filosofia que enfrentam estes problemas no seu quotidiano, como para os estudantes que, na sua formação para o ensino de Filosofia, podem descobrir aqui interrogações e respostas muito úteis na sua formação em Didáctica da Filosofia. 


\section{3.}

O tempo não nos permite agora aprofundar os tópicos dos textos e dos comentários de cada um destes grupos. E eles seriam muito ricos e diversificados, como, no que se refere ao tópico específico do ensino da Filosofia, o demonstra o exemplo de Musonius Rufus, com a importância reconhecida à necessidade de as mulheres aprenderem Filosofia, o texto de Agostinho, fazendo apelo a uma autêntica maiêutica interior na aprendizagem filosófica, a articulação estabelecida por Espinosa entre liberdade de pensamento e investigação e ensino oficial no espaço público da Escola ou da Universidade (questão retomada também, ainda que em termos ligeiramente diferentes, por Maria Zambrano), a perspectivação de Ortega y Gasset quando, prévio ao ensino da Filosofia, reclama a instauração da necessidade da Filosofia da parte de qualquer aprendiz ou amante da sabedoria, restaurando no estudante o desejo originário do próprio filósofo, o primado da dimensão crítica e da atitude crítica na iniciação ao filosofar postulada por António Sérgio, o desafio constituído pelo ensino da Filosofia às crianças formulado, gizado e aprofundado por Matthew Lipman que postula a educação para o pensamento como uma componente incontornável e insubstituível de toda e qualquer educação, entendida como um processo de desenvolvimento de competências cognitivas, sociais e afectivas, a vocação para a legislação prática e política inerente ao filosofar e aos actos com que ele se inicia, reclamada por Lyotard, a ecologia dos conceitos que permanentemente são criados na actividade filosófica, e cuja rede inter-relacional é, assim, inerente ao ensinar e ao aprender Filosofia na perspectiva de Deleuze, para não citar senão alguns dos autores seleccionados e comentados. Há, no entanto, neste grupo de autores cujos textos e cujos comentários se debruçam especificamente sobre o ensino ou a aprendizagem da Filosofia, algumas ideias que, pela sua actualidade e pela sua pertinência, não posso deixar de sublinhar de um modo especial. Refiro, em primeiro lugar, o excelente texto de Tomás de Aquino e as quatro atitudes que recomenda a quem se dedica à aprendizagem da filosofia e do filosofar: a escuta, múltipla nas suas vozes e nas suas fontes, a investigação, como requisito para qualquer progresso filosófico, a prudência como requisito de um progresso no questionamento, como virtude daquele que questiona e como condimento indispensável do que é questionado, e a meditação que corresponde ao acto de mastigar na assimilação da comida e que aqui se transpõe para a assimilação do alimento que dá vida ao intelecto. Um destaque especial merecem também os textos e respectivos comentários de Kant e de Hegel. O de Kant, privilegiando a via da aprendizagem da Filosofia como uma via da aprendizagem do pensar, contextualizada de uma forma exímia no pensamento do autor por Leonel Ribeiro dos Santos, segundo o 
qual uma diferente concepção de Filosofia e do filosofar determina uma diferente concepção correlativa do que é ensinar e aprender Filosofia, fazendo do professor de Filosofia um "parteiro de pensamentos"; o de Hegel, que, numa perspectiva que parece mas não é oposta, acentua os conteúdos que o ensinar e o aprender da Filosofia comportam, na referência aos mestres do passado e aos conceitos que nos deixaram, mas que são indissociáveis do respectivo método que é a sua alma, e que, consequentemente, faz com que a aprendizagem da Filosofia também não se possa desligar da modelação da capacidade de reflectir inerente a todo o autêntico filosofar, como também refere Adriana Veríssimo Serrão no seu comentário a este texto e a este autor. Muito interessante é também o texto de Feuerbach, em que a intrínseca dimensão comunicativa da Filosofia é sublinhada ("os modos de demonstração e do raciocínio", diz o autor, "não são formas da razão em si [...], não são formas do acto interior de pensar e de conhecer; são apenas formas de comunicação, modos de expressão, apresentações e representações, manifestações do pensamento" (p. 174). Fica assim claro por que razão a filosofia é ensinável: é-o porque ela é essencialmente expressiva e comunicativa, porque é intrinsecamente dialógica, começando todo o ensino da filosofia por um diálogo consigo mesmo e por um ensino a si próprio que depois se prolonga num diálogo com o outro e um ensino ao outro, configurando a actividade filosófica como uma actividade eminentemente intersubjectiva, como refere Adriana Veríssimo Serrão no seu comentário. Numa linha idêntica se projecta o texto de Levinas quando afirma que "o adquirido do estudo é um outro eu, que me responde, que me arranca à solidão e a quem tenho que responder" (p. 252), estabelecendo-se uma interessante analogia entre o estudo da Tora e o estudo da Filosofia, a aprendizagem da Tora e a aprendizagem da Filosofia. É, com essa analogia, introduzida, no contexto do ensino e da aprendizagem da Filosofia a noção de fidelidade e a noção de responsabilidade. Como refere Cristina Beckert, se "transmissão não é repetição, mas interpretação", então, ser fiel à Tora, e também ser fiel à Filosofia, é ao mesmo tempo ser-lhe infiel, pois isso implica "acrescentar-lhe algo que ainda não foi dito" (p. 252), abrir-se à multiplicidade de sentidos que o texto viabiliza e, também assumir, por isso mesmo "a função ética" do acto de interpretar. Finalmente, neste conjunto de textos, e perdoem-me os outros autores e os outros comentadores por não lhes fazer a referência mais pormenorizada que também mereciam, gostaria de chamar a atenção para o programa desenhado pelo texto de Derrida com os seus sete mandamentos no ensino da Filosofia: $1{ }^{\circ}$ Protestar contra a submissão do acto filosófico a toda a finalidade exterior, sem prescindir da sua dimensão crítica e avaliadora, constitutiva de sentidos e de um sentido final; $2{ }^{\circ}$ Protestar contra 
o fechamento da Filosofia, sem prescindir de reivindicar a sua especificidade própria; $3{ }^{a}$ Articular permanentemente a investigação e o questionamento filosóficos com o seu ensino; $4 .^{\circ}$ Não reduzir a norma filosófica à sua expressão institucional, reconhecendo como sua prerrogativa essencial a liberdade e a obediência à força do pensamento; $5 .^{\circ}$ Articular a necessidade de um mestre no ensino da Filosofia com a autonomia do pensamento e a estrutura essencialmente democrática da comunidade filosófica; $6{ }^{\circ}$ Articular a duração com a contracção no ensino da Filosofia, reconhecendo o tempo longo que requer mas também a organização contractiva em que se concretiza; $7 .^{\circ}$ Saber conciliar a presença do mestre no ensino da Filosofia com o seu apagamento, dada a tradição autonomista e autodidáctica da Filosofia. É, como vemos, todo um programa que aqui se presentifica com desafios cuja actualidade, nos tempos sombrios e tecnocráticos que vivemos, é por demais evidente.

4.

O fundamento para todas estas opções e estratégias no ensino da Filosofia é-nos dado, entretanto, pelo segundo maior bloco de textos que esta colectânea nos apresenta: aqueles em que os filósofos, ao longo da História, foram reflectindo sobre a natureza da filosofia e as suas principais dimensões. São muitos e incontornáveis os tópicos referidos por estes autores e pelos seus comentadores: Platão faz um elogio à sabedoria na sua apologia de Sócrates, entendida, como refere Maria José Vaz Pinto, enquanto "consonância entre o que se pensa, o que se diz e o modo como se vive"; Aristóteles sublinha a atitude de espanto, que é sempre uma escuta do outro, do mundo e das coisas, como raiz de toda a procura filosófica, instaurando a Filosofia como diálogo com o mundo, com a vida, com os homens e com os outros pensadores; Epicuro, na sua articulação entre filosofia e felicidade, faz um elogio à prudência como a virtude subjacente a toda actividade filosófica; Leibniz reforça também a dimensão comunicativa da Filosofia, como pensamento que é expressão da própria força expressiva da realidade, permitindo assim fundir, nas palavras de Adelino Cardoso, uma pedagogia expressiva como uma pedagogia da aprendizagem; mas se o ser é, em Leibniz, expressão, a ideia de sistema em que se diz pressupõe, como nota Schelling, um antagonismo irredutível, o que introduz a própria conflitualidade no saber que o diz, sendo todo o sistema filosófico constituído por uma pluralidade de sistemas, como condição para a própria progressividade do saber, ao mesmo tempo que exige um espírito de nudez, de desconstrução, de remoção de certezas, para o acto de iniciação filosófica que postula, quase eckhartianamente, o abandono do próprio Deus, símbolo da nudez total: "Quem quiser verdadeiramente filosofar deve abandonar toda a 
esperança, toda a exigência e todo o desejo, é preciso nada querer, nada saber, sentir-se inteiramente nu e pobre, tudo sacrificar para tudo obter" (p. 158); já a entrevista de Paul Ricoeur, ao recolocar a palavra no centro da Filosofia, a palavra não só dos filósofos, mas também dos poetas, perspectiva a filosofia como uma actividade que nunca começa do nada. Dir-se-ia que, mesmo seguindo o conselho de Schelling em ordem a um completo desnudar-se, é ainda e sempre a palavra e os seus vestígios, aquilo que os outros disseram mesmo fora de uma reflexão aprofundada, que constitui também matéria do filosofar, o que obriga o mestre de Filosofia a estar atento a todos os vestígios da palavra humana, que, assim, constitui o pressuposto de todo o filosofar, a condição do seu exercício, o ponto de partida para todo o ensino e para toda a aprendizagem; se a este testemunho de Ricoeur acrescentarmos o testemunho de Foucault, que estabelece o ensaio como a vocação da discursividade filosófica, entendido na sua dinâmica auto-reflexiva com uma dimensão praxística, enquanto "ascese" ou "exercício de si" do pensamento ou, como refere José Aredes no seu comentário, entendendo a reflexão como "uma ética do cuidado de si como prática da liberdade" (p. 333), redefinido a filosofia a partir da sua dimensão "onto-etho-poiética", encontramos o necessário e indispensável complemento que permite articular a filosofia com o exercício da existência e, por isso mesmo, a iniciação filosófica como a iniciação à existência plena, na linha já aberta pelo Sócrates de Platão.

\section{5.}

O conjunto de textos que, mais do que perspectivar o ensino da Filosofia, perspectivam a natureza do próprio ensino e da própria educação são um complemento necessário desta estratégia que visa promover uma reflexão sobre o ensino e a aprendizagem da Filosofia e do filosofar tomando como base as reflexões dos próprios filósofos. É, por exemplo, o caso de Rousseau, que dá ao discípulo a dignidade de alguém que tem o direito a aprender em liberdade e a ter prazer na educação (e quantas críticas não poderiam ser feitas, deste ponto de vista, ao ensino da Filosofia como uma obrigação árdua e pesada e não como um exercício da alegria) e é também o caso de Nietzsche que faz da educação uma pedagogia da libertação e do filósofo um educador para a liberdade, agindo "contra o tempo" e "sobre o tempo", "em benefício de um tempo por vir". A estas dimensões, juntará Bertrand Russell, por um lado, o tópico da democracia, ou seja, da universalidade, e, por outro, a dimensão do amor, ao afirmar que "o conhecimento exercido pelo amor é aquilo de que o educador necessita e o que o aluno deve adquirir" (p. 191). Finalmente, sobre o ensino, não já na sua natureza, mas na contextualização actual dos seus sujeitos e do seu processo, revela-se profundamente sugestivo 
tanto o texto de Michel Serres, que recorre ao sugestivo tema de "la petite poucette", como o respectivo comentário de Fernando Rua, meditando sobre a revolução da educação na era digital, com a revolução cultural, a geração mutante e a redefinição do saber que essa era digital implica e que, como é óbvio, não poderá deixar de se repercutir no próprio ensino da Filosofia. O livro encerra com um texto de John Searle, comentado por Pedro Galvão, que, ao mesmo tempo que é sobre a natureza do ensino, não deixa de ter repercussões relativamente ao ensino da Filosofia. Por detrás deste texto e, sobretudo do seu comentário, está uma aspiração a uma neutralidade da filosofia como realização suprema da vocação filosófica. Devo dizer que tenho muitas dúvidas sobre tais reivindicações de neutralidade: penso que uma coisa é evitar a instrumentalização da Filosofia e outra, bastante diferente, é entender que o filósofo, no exercício de um pensamento crítico, tem de ser um cidadão descomprometido e axiologicamente neutral em relação aos valores culturais e políticos de que se entretece a cidade dos homens. Se, mesmo em ciência, a neutralidade é muitas vezes a máscara de compromissos inconfessados, muito mais o será em Filosofia, sendo preferível a assunção específica desses compromissos, à sua veiculação de modo implícito, velado ou mesmo inconsciente. Mas até sob este ponto de vista esta colectânea é, por isso mesmo, um livro plural e aberto: nem as opiniões veiculadas por cada um dos filósofos têm de ser unanimemente aceites, nem as posições dos respectivos intérpretes são inquestionáveis. A Filosofia é, de modo eminente, uma actividade crítica, e a leitura dos textos aqui reunidos é sempre um convite ao exercício crítico do pensamento.

Saúdo por isso, mais uma vez, a publicação desta obra e agradeço às suas coordenadoras e a todos aqueles que colaboraram neste projecto o desafio a uma reflexão lúcida e despreconceituosa como deve ser todo o exercício da filosofia em liberdade e em democracia. 